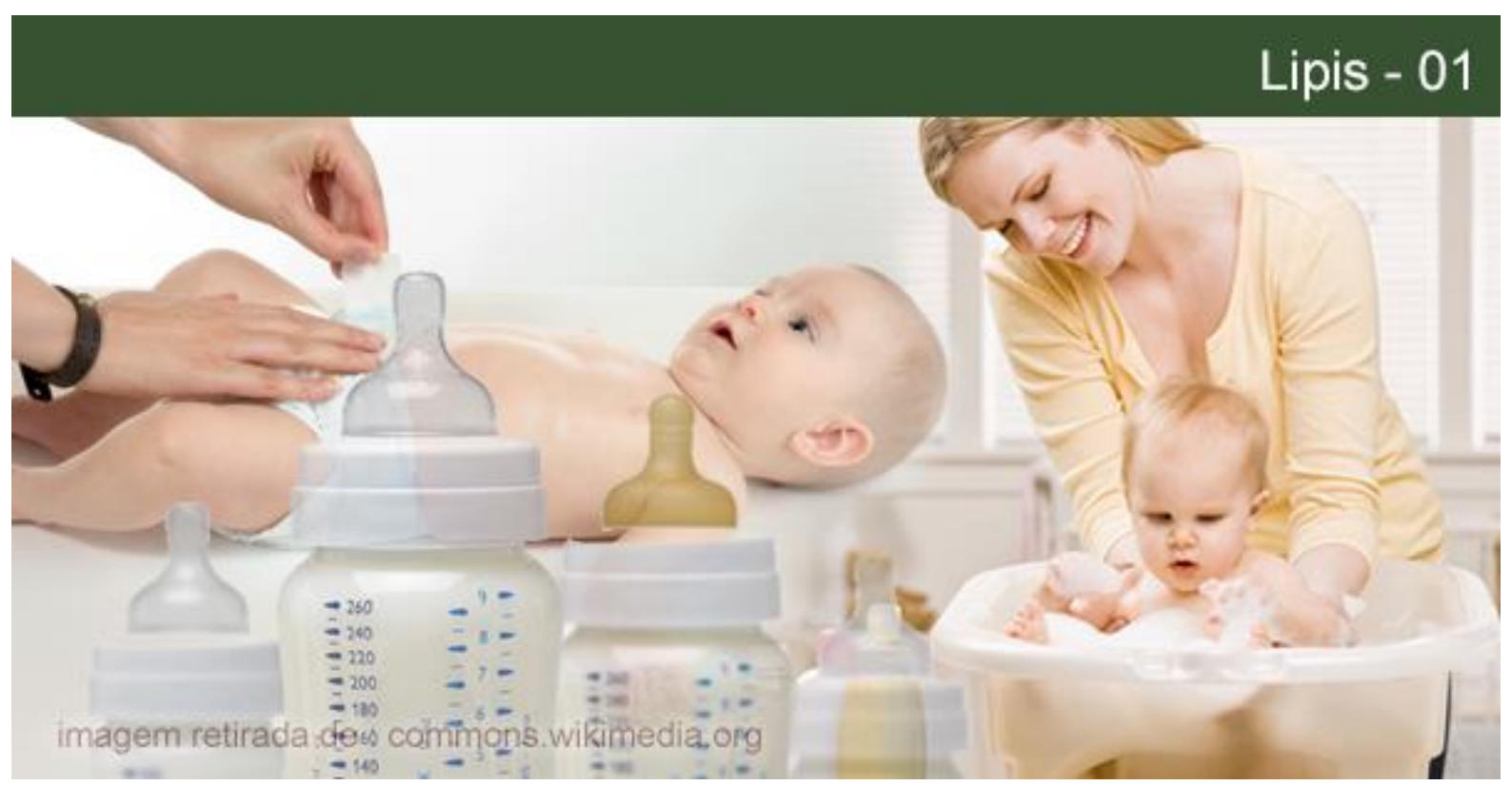

\title{
APOIOS COMPRADOS: FORMAS CONTEMPORÂNEAS DE SUPORTE À MATERNAGEM
}

\author{
Roberta Corrêa Lanzetta \\ Mestranda do Programa de Pós-Graduação em Psicologia Clínica da Pontifícia Universidade Católica do Rio \\ de Janeiro (PUC-Rio) e Psicologa Clínica. Email: r.lanzetta@hotmail.com.
}

\section{Maria Inês Garcia de Freitas Bittencourt}

Doutora em Psicologia Clínica pela PUC-Rio, Professora do Departamento de Psicologia da PUC-Rio e Supervisora de estágio de clínica infantil do SPA da PUC-Rio. Pesquisadora do Laboratório Interdisciplinar de Pesquisa e Intervenção Social, LIPIS, PUC-Rio.Email: mines@puc-rio.br.

Resumo: O que mulheres de hoje buscam ao procurar serviços, ou "cursos", que se dispõem a ensinar técnicas de maternagem? Propomos aqui, a partir de dados encontrados em entrevistas, destacar os sentimentos de insegurança e incerteza decorrentes das representações sociais relativas ao desempenho da função materna, considerada como um desafio a ser enfrentado com eficiência e sucesso. Levando em conta os valores presentes no contexto histórico-social contemporâneo, propomos um diálogo com a Psicanálise, em especial destacando as ideias de Winnicott.

Palavras chave: Maternidade. Pós-modernidade. Incerteza. Sociedade de consumo

\section{PURCHASED SUPPORT: CONTEMPORARY ASSISTANCE FOR MOTHERHOOD}

Abstract: What do contemporary women seek when they look for services that teach them mothering techniques? We propose here, from data found in interviews, to highlight the feelings of insecurity and uncertainty arising from social representations regarding the performance of maternal role, considered as a challenge to be faced with efficiency and success. Taking into account the present values in the contemporary social context -, we propose a dialogue with psychoanalysis, specially selecting Winnicott's ideas.

Key words: Motherhood. Postmodernity. Incertitude. Consumer society.

\section{Introdução}

\section{POLÊM!CA | Revista Eletrônica da Uerj}


Nos dias de hoje é reconhecida em todo mundo ocidental a noção de que os pais são responsáveis pelo desenvolvimento da criança, e seu papel no amadurecimento da criança parece ser algo de ordem natural. Considerando-se os atravessamentos da cultura e sabendo que na modernidade líquida os imperativos do consumo estão presentes em diversos aspectos da vida, tendo como consequência para muitos indivíduos a troca de valores do "ser" pelo "ter", nos propusemos a pesquisar o que mulheres de hoje buscam ao procurar serviços, ou "cursos", que se dispõem a ensinar técnicas de maternagem.

Podemos pensar diversos aspectos como motivação para a busca de um curso para casais grávidos nos dias de hoje. Propomos aqui priorizar os sentimentos de insegurança e incerteza decorrentes das representações sociais relativas ao desempenho da função materna, considerada como um desafio a ser enfrentado com eficiência e sucesso. Levando em conta os valores presentes no contexto histórico-social contemporâneo, propomos um diálogo com a Psicanálise, em especial destacando as ideias de Winnicott, uma concepção atual sobre as primeiras relações mãe-bebê, de modo a problematizar alguns comportamentos observados em futuras mães frente a questões referentes à maternidade.

\section{A maternidade ontem e hoje: transformações na família e na maternagem}

O modelo de família que predominou durante um longo período da modernidade vem sofrendo alterações ao longo do tempo. A família transformou-se profundamentea partir do momento em que modificou suas relações internas com a criança. Neste período, juntamente com a Revolução Industrial, inicia-se uma revolução na afetividade, que passa a concentrar-se no interior da família (ARIÈS, 1978).

Roudinesco (2003) separa a evolução da família em três momentos: família tradicional, família moderna e família pós-moderna. Segundo a autora, a família moderna caracteriza-se pelo amor romântico, reciprocidade afetiva e pela responsabilidade dos pais e do Estado em relação à criança. Roudinesco problematiza questões observadas na contemporaneidade, ressaltando como, em contraponto à antiga segurança representada pelo casamento, a família contemporânea tem como característica a instabilidade, a incerteza de dois indivíduos que buscam relações íntimas, realização sexual e pessoal. Chama atenção também para o fato de que para a mulher contemporânea o trabalho não é apenas uma 
necessidade, mas uma fonte de realização pessoal, e os filhos passam a constituir-se numa escolha.

Assim, junto com as transformações familiares que ocorreram ao longo dos séculos, podemos pensar as mudanças surgidas no que diz respeito à maternagem, associando-as às transformações sociais. Elisabeth Badinter (1985) propõe um olhar histórico para que possamos compreender o que possibilitou a ideia de maternagem associada à ternura que encontramos nos dias atuais. A autora francesa problematiza a questão do amor materno considerado como um instinto, ou seja, uma tendência inata e comum aos indivíduos, intrínseca ao comportamento feminino. Analisando a evolução das atitudes maternas, verificase que o interesse e o cuidado em relação à criança nem sempre existiram, e, além disso, podem variar de acordo com a época e segundo a classe social.

A partir do século XVIII a maternidade é exaltada, passando de um dever para algo desejado. Nessa nova perspectiva a mãe deverá desenvolver um forte vínculo com seu filho de forma dedicada e prazerosa. Cada vez mais os pais se sentirão responsáveis pela felicidade dos seus filhos. Desse ponto de vista, como mostra Badinter (1985) exaltam-se interminavelmente as doçuras da maternidade, que deixa de ser um dever imposto para se converter na atividade mais invejável e mais doce que uma mulher possa esperar.

A principal transformação no que se refere à maternidade é, sem dúvida, a mulher passar a amamentar o próprio filho. As trocas afetivas entre mãe e bebê ganham novo valor, possibilitadas através dos carinhos físicos. Como consequência dessa nova relação de afeto, a criança torna-se o principal objeto de preocupação dos pais.

Em relação às transformações da maternidade no contexto brasileiro, podemos citar estudos de Moura \& Araujo (2004), nos quais observa-se que no Brasil, do mesmo modo como na Europa, a partir do final do século XIX, a chegada de um novo ser humano no seio da família foi vivida de nova maneira pelas mulheres. Assim a maternagem ocupou a vida da mulher durante boa parte do século XX, tornando-se uma experiência complexa, que embora estivesse envolta de alegria e orgulho por ser considerada importante, prestigiada pela sociedade, também gerou de forma inconsciente um mal estar por fazer com que muitas mulheres se sentissem culpadas e frustradas quando não desejavam desempenhar tal papel. Mesmo quando desejada, devido à exigência de aproximar-se do "modelo perfeito", a vida da mãe oscilava entre a felicidade e satisfação e a insatisfação e frustração. Conforme a função 
materna ampliava-se, frisava-se que a devoção fazia parte da natureza feminina, e que dela advinha sua felicidade, ainda que a mulher conseguisse desempenhar outra função além de mãe.

O papel do pai, inicialmente identificado com a autoridade, também se modificou ao longo do tempo. Historicamente são atribuídas algumas justificativas à ausência paterna no convívio cotidiano, evocando-se a incapacidade masculina para educar física e moralmente os filhos, a falta de tempo devido ao trabalho, o fato de não ser uma ligação tão "natural" quanto a da mulher, por ela ter gerado em seu ventre o bebê, dentre outras. Podemos observar que a imagem de pai provedor, responsável por manter a família e seu conforto sobrevive até os dias atuais. Ainda está presente no imaginário coletivo a ideia de que a formação de uma criança é da responsabilidade da mulher. Sendo assim, a participação afetiva do homem seria menos importante, tornando-se acessória. Somente com o acesso das mulheres às carreiras que em determinada época foram exclusivamente masculinas, é que certa igualdade vem sendo estabelecida. Surge a manifestação de um desejo por parte das mulheres de que os homens, anteriormente vistos como provedores, passem a compartilhar do amor pelos filhos e dos sacrifícios que envolvem a criação dos mesmos, deixando de lado o imaginário que certas atribuições são especificamente maternas.

No que se refere ao Brasil, pesquisas recentes (BARBOSA \& ROCHA-COUTINHO, 2007; ROCHA-COUTINHO, 2000, 2003, 2004; JABLONSKI, 2010) apontam que o trabalho feminino com o passar dos anos torna-se uma fonte de satisfação, realização e como um meio de desenvolver e afirmar a personalidade. Cada vez mais as mulheres escolhem de forma voluntária trabalhar fora de casa. À medida que as mulheres qualificam-se e aumentam seu nível de instrução assumindo posições profissionais importantes, maior é a possibilidade de as mesmas não se disponibilizarem para as tarefas domésticas.

Sendo assim, surge o desejo de partilhar com o cônjuge das responsabilidades tanto da casa quanto da criação dos filhos. Pesquisas (BARBOSA \& ROCHA-COUTINHO, 2007; BRASILEIRO, JABLONSKI \& FÉRES-CARNEIRO, 2002; ROCHA-COUTINHO, 2003, 2004; JABLONSKI, 1988, 1996, 2001, 2003, 2010) apontam contudo que mesmo a mulher trabalhando fora, a maior parte das tarefas domésticas e parentais ficam sob sua responsabilidade. No entanto, ainda de acordo com tais pesquisas, já é possível observar 
atualmente um desejo do homem em participar tanto da gravidez quanto das tarefas da maternagem que em outros tempos foram reservadas exclusivamente à mãe.

\section{Uma concepção psicanalítica contemporânea sobre a maternidade}

As ideias desenvolvidas por diversos autores no campo da Psicanálise traduzem os valores presentes nas representações contemporâneas do papel da mãe no desenvolvimento de uma criança. Laplanche e Pontalis (2001) corroboram essa temática ao afirmar que a mãe "influencia assim de forma decisiva a estruturação do psiquismo, destinado a constituir-se inteiramente na relação com outrem". Essa relação assinala, no âmbito da teoria psicanalítica, a supremacia materna no início da vida de um bebê. É relevante sinalizar que o termo "mãe" refere-se a qualquer pessoa que assuma a função de cuidar do bebê.

Assim, a partir de sua experiência como pediatra e psicanalista, Winnicott construiu uma teoria do desenvolvimento emocional primitivo dando ênfase a elementos da relação mãe-bebê fundamentais e indispensáveis para o amadurecimento do ser humano dentro de um determinado contexto de provisão e cuidado. O autor descreve um processo que vai de um estado inicial em que o bebê encontra-se fusionado ao ambiente, até o reconhecimento da externalidade, possibilitando o relacionamento entre pessoas totais. Para Winnicott (1956/2000), a maternagem é elemento fundamental para a constituição da subjetividade da criança.

Pertencendo a outra escola psicanalítica, Piera Aulagnier (1989; 1990) e Françoise Dolto (1984) reforçam a importância do desejo materno sem o qual um bebê não se tornará um sujeito.

A criança objeto de estudo da psicanálise, descrita através dos laços de afeto, é, consequentemente, a que cresce graças aos cuidados maternos e ao apoio de seus desejos sobre a satisfação de suas necessidades.

Winnicott (1988), ao discorrer sobre os momentos iniciais do desenvolvimento, afirma que num primeiro momento o adulto cuidador é uma extensão dos ritmos da criança tanto em relação aos aspectos corporais quanto aos psicológicos. A preocupação materna primária, termo formulado pelo psicanalista inglês, diz respeito a um estado de sensibilização que surge na mulher nas últimas semanas de gestação e perpetua-se até os primeiros meses do nascimento do bebê - como forma de elaboração ao exercício da função materna - que tem

\section{POLÊM!CA | Revista Elerơnica da deri}


como característica o investimento e foco de sua atenção voltado em todos os aspectos para o bebê, tornando-se sensível às necessidades do mesmo. Os conhecimentos não precisam surgir de forma intelectualizada a partir de determinada parte da mente onde há palavras para tudo, os entendimentos devem vir de um nível mais profundo, que será proporcionado através da sutil e delicada relação que existirá entre ela e o seu filho. Sendo assim, de acordo com Winnicott (1988), a mãe poderá aprender sobre bebês com o seu próprio bebê. Para o psicanalista inglês, a dedicação materna, tanto do ponto de vista físico (através do holding) como psicológico (através da relação empática e da adaptação sensível às necessidades do bebê), funciona como uma espécie de membrana protetora fundamental para que se articule um espaço psíquico.

Porém, pode pesar sobre as mães a responsabilidade de criar seus filhos, tal a importância atribuída a elas por desempenharem esse papel fundamental. Estamos pensando em relação à mulher, mas o pai também pode sofrer ansiedades perante essa tarefa. Dúvidas sobre a capacidade de criar uma criança saudável poderão surgir, gerando a necessidade de apoiar-se em receitas prontas (DIAS, 2014).

Partindo da premissa que um bebê não pode existir sozinho e que para que passe a existir seja necessário pertencer a uma relação, desempenhar os cuidados de forma intuitiva torna-se fundamental para que o vínculo seja estabelecido. Dessa maneira, por mais que aprendam como trocar fralda, dar banho e amamentar, um livro, manual ou saber intelectual não dará conta da formação de um sujeito, pois para que isso ocorra o bebê precisa sentir que existe alguém envolvido amorosamente em seus cuidados. Da leitura da obra de Winnicott depreende-se que é sempre um relacionamento vivo entre duas pessoas que abre espaço para o crescimento. A aplicação de conceitos e regras aprendidas teoricamente torna a relação mecânica, monótona e robotizada, o que não facilita a intersubjetividade. Para que o recémnascido cresça saudavelmente basta que o reconheçam humanamente, proporcionando uma estabilidade através dos cuidados que respeitem sua dinâmica.

Ainda que os laços afetivos entre mãe e bebê pareçam surgir de forma tão natural desde certo período ao longo da gestação, para que esse estado de identificação da mulher com o filho possa ocorrer e ela consiga realizar os cuidados essenciais para que o mesmo tenha um desenvolvimento saudável é necessário que haja um contexto que forneça a ela um suporte. Neste sentido, tanto se fala a respeito da importância do cuidado materno que pode

\section{POLÊM!CA | Revista Eletronica da aej}


passar despercebida a importância do pai nesse momento primordial. Winnicott (2014) apresenta um texto denominado $E$ o pai?, que traz reflexões sobre qual papel caberia ao homem nessa fase. Um aspecto fundamental do pai refere-se ao apoio dado à mãe, para que ela possa desempenhar seu papel de cuidadora.

Após a inserção no mercado de trabalho, as mulheres passaram a alcançar posições no cenário econômico e profissional tendo como consequência um acúmulo de funções pessoais e profissionais. As representações sociais do papel da mãe atualmente contrastam com o que ocorria em décadas anteriores, quando se tinha a visão de que a mulher era a dona de casa, cuja função primordial se referia ao cuidado com as crianças. Diante desse novo cenário, a escolha pela maternidade vem acrescentar-se a outros valores importantes na vida da mulher. Como dar conta desses múltiplos papéis? O que é ser uma mãe suficientemente boa na contemporaneidade?

Considerando-se os atravessamentos da cultura em diversos aspectos da vida, torna-se pertinente investigar o processo denominado preocupação materna primária - no qual a dignidade do lactente é priorizada - respeitando assim o seu ritmo em uma época em que, como diz Bauman (1998), os valores são líquidos, individualistas, materialistas, onde as relações são frágeis e prevalecem os sentimentos de incerteza e insegurança. Nesse sentido, somos instigadas a pesquisar o que mães buscam ao procurar serviços que se dispõem a ensinar técnicas de maternagem.

\section{A liquidez pós-moderna}

De acordo com Bauman (1989), na vida contemporânea os projetos de vida individuais têm dificuldades em encontrar terreno estável onde possam ancorar-se. As propostas de continuidade e de solidez, que eram a marca das estruturas modernas, não se fazem presentes nos dias atuais; o sentimento que predomina nesse momento é a sensação de uma nova incerteza, que diz respeito a maneira com que vive-se em um mundo instável, fluido, em constante movimento, onde as regras não param de mudar ao decorrer do próprio percurso.

Surge nesse contexto a necessidade de estar sempre atualizado; para esse fim exige-se uma qualificação permanente e a educação supervaloriza-se por ser considerada a única maneira de conseguir um "lugar ao sol" diante de um mundo do trabalho extremamente concorrido. Ainda que, do mesmo modo que os objetos de consumo, os conhecimentos sejam 
considerados obsoletos rapidamente para que sejam substituídos por novos, o aprendizado rapidamente torna-se antigo, uma vez que cada vez mais são solicitadas novas habilidades.

Podemos nos questionar sobre como tais transformações podem influenciar a relação pais e filhos nos dias de hoje. Mizrahi (2004) pontua como o mundo do consumo e dos serviços passa a interferir na relação pais e filhos, fazendo que estes se sintam inseguros em relação a sua forma de cuidar, que sabemos ser singular e de suma importância para o desenvolvimento saudável do indivíduo, constituindo as bases para a criatividade quando vivenciada na parentalidade.

Paradoxalmente aos sentimentos de medo, falta de esperança em relação ao futuro e a insegurança presentes no cotidiano, nos tempos contemporâneos somos incentivados a ser sempre saudáveis, felizes nos mais diversos aspectos e durante a maior parte do tempo. Essas exigências pós-modernas trazem expectativas que levarão a recorrer a mídia como fonte de orientação. Surge então, a figura do especialista como referência, fonte de segurança e credibilidade.

De acordo com Almeida \& Jablonski (2011), os especialistas estão presentes nos dias de hoje, com pareceres disponíveis durante o tempo todo através dos diferentes meios de comunicação, dentre eles o da literatura de massa, ou seja, os livros de autoajuda. Esse tipo de literatura tem conquistado lugar como uma das principais fontes de informação, tornando-se um guru em formato de manual com a finalidade de explicar aos leitores o que fazer e de que maneira, substituindo valores em relação aos modos de ser e de viver que outrora referiam-se à família e à igreja.

Não é de se admirar que dentro deste contexto surjam diversos cursos para orientar mulheres incertas quanto ao seu papel, em busca de conhecimento sobre a maternidade.

\section{Conhecendo um novo universo}

A partir da perspectiva teórica acima descrita, procuramos investigar o que motivou um grupo de gestantes a buscar pela ajuda de um curso para casais grávidos. Realizamos uma pesquisa qualitativa, consistindo em entrevistas semiestruturadas realizadas individualmente no local escolhido pelas próprias entrevistadas, conforme a disponibilidade, conveniência e preferência das mesmas. 
Nosso estudo contou com a participação de 07 mulheres, dos segmentos médios da população carioca, vivenciando as últimas semanas de gestação (da 33a à 39a semana), que procuraram por orientação em um "curso para casais grávidos". As idades das entrevistadas variam de 32 a 39 anos, todas possuem formação superior e estão esperando seu primeiro filho(a). Um dado importante é que todos os homens assistiram as aulas junto com suas companheiras.

A proposta desses cursos é "ensinar", esclarecer e tirar dúvidas a respeito de diversos aspectos tanto da gravidez como da maternidade e dos cuidados com o bebê. Cursos desse tipo podem ser encontrados nas "principais" maternidades do Rio de Janeiro como também podem ser lecionados por pediatras, obstetras, enfermeiras, espaços especializados em atividades para gestantes ou por alguém que possua certa experiência no cuidado com bebês. Devemos diferenciar o que estamos denominando "curso para casais grávidos" dos grupos oferecidos gratuitamente às gestantes em diversos hospitais em seus serviços de psicologia, bem como algumas instruções advindas dos bancos de leite.

No local escolhido como campo de pesquisa, os cursos são subdivididos em módulos, cada aula tendo de 3 a 4 horas de duração. Todo o ambiente é organizado para que os futuros pais sintam-se ambientados e familiarizados com o universo infantil.

Os participantes recebem um material impresso para que possam acompanhar as instruções e se necessário anotar algo. Ao longo da aula as dúvidas são respondidas e um bebê de brinquedo serve como modelo para que o casal possa "treinar" como dar banho, trocar as roupas e as fraldas disponibilizadas para os exercícios, assim como aprender algumas posições de amamentação.

Entendemos que por tratar-se de uma situação nova para alguns casais, a mesma possa vir acompanhada por dúvidas, questionamentos e inseguranças. Mas seria possível construir um manual para aliviar essa angústia? A maternagem pode ser aprendida? O que é ser uma boa mãe?

A partir da análise dos relatos obtidos através das entrevistas puderam ser selecionados alguns temas recorrentes nas falas das participantes, formando categorias de análise. Nesse artigo iremos nos ater às motivações para buscar o curso.

\section{POLÊM!CA | Revista Eletronica da veri}


De acordo com as entrevistas, as principais motivações se referem à valorização da informação frente a sentimentos como a insegurança diante da situação nova, que gera medos, principalmente no que diz respeito à amamentação.

“A gente (...) acredita que quanto mais informação você tem, mais conhecimento sobre o que está acontecendo você tem, isso te dá até um apoio psicológico pra você encarar esse momento de transformação." (T).

Percebemos que as mulheres sentem necessidade de procurar por um especialista para garantir um saber acerca da maternagem. É como se para ser mãe houvesse a necessidade de qualificar-se, acreditando que para tal exista um modelo de excelência.

Outra razão de sentir a necessidade de informações adquiridas por meio das aulas deve-se ao fato da perda do lugar da tradição, das figuras de referência presentes outrora na própria família, que hoje pode ser substituída pelo saber técnico/especializado.

\footnotetext{
"A minha mãe já faleceu e a mãe dele a gente não pode contar, então o fato de não ter uma pessoa que a gente confie pra dar um suporte, eu acho que deixou a gente um pouco inseguro no sentido de como a gente vai fazer." (M).
}

Também a insegurança e a incerteza, sentimentos presentes no cotidiano de quem habita o mundo contemporâneo, foram aspectos que motivaram nossas entrevistadas a buscar ajuda.

\footnotetext{
“Acho que foi mais pra ter segurança de que eu tava fazendo a coisa certa. Tô pelo caminho certo, confiança e a segurança com certeza pro curso foi muito bom. ”(M).

"Eu perguntava tudo, exatamente tudo, das coisas mais bobas do tipo qual o sabão que você usou pra lavar as roupinhas até coisas mais... mais... poxa o que que você sentia, você tinha isso, você tinha aquilo (...) Acho que isso tá muito calcado na inseguranca porque realmente é um assunto que voce nao sabe, e que.. e que po, voce quer muito saber ne? Agora grávida eu sinto só essas incertezas, só essas inseguranças.. " (L).
}

O módulo do curso que diz respeito à amamentação é um dos mais procurados, talvez por ser um tema onde as mães não encontrem muitas informações, fazendo com que não se sintam “capacitadas" para tal tarefa. A partir das falas de nossas participantes podemos observar que ainda há um resquício daquela ideia de maternagem associada ao instinto, principalmente no que diz respeito à amamentação.

Frequentes foram as menções à amamentação e à fragilidade do bebê.

\section{POLÊM!CA | Revista Eletronica da Ueji}




\begin{abstract}
"A amamentação era um assunto que eu não encontrava. E a amamentação eu acho que as pessoas ficavam meio apoiadas naquele... ah a gente vira bicho, na hora você vai ter um instinto animal que vai te ajudar, que você vai saber na hora e você vai fazer. Então eu sempre me sentia muito desinformada e era um assunto que, que ali sim eu falava, cara eu preciso saber isso um pouco mais porque pode não acontecer naturalmente. Eu posso não me transformar nesse bicho que todo mundo fala que você vai se transformar e aî?" (L).
\end{abstract}

\title{
Conclusão
}

Levando em conta que a ideia de maternagem associada à ternura e ao afeto nem sempre esteve presente nos ideais femininos, tratando-se então de uma construção social, constatamos que, hoje em dia, os ideais de capacitação e excelência têm influenciado o imaginário de mulheres que caracterizamos como consumidoras de classe média/alta, a respeito do que seria a "maternagem perfeita". A consequência disso aparece na procura por cursos privados que "ensinem" e "qualifiquem" não só a mãe mas também seu companheiro a desempenhar os cuidados para com o recém-nascido.

Nesta pesquisa foi ressaltado que os atravessamentos da sociedade de consumo - que tem por pano de fundo os sentimentos de incerteza e insegurança - podem influenciar uma etapa primordial da vida do ser humano, a saber: o nascimento de um filho. Torna-se relevante a necessidade de apoios a essa mãe, que também precisa ser cuidada, sentir-se segura e amparada para desempenhar papel tão primordial. Tal apoio deveria ser ofertado por seu marido, família e amigos próximos, mas devido à "falência" das narrativas presentes outrora, as pessoas passaram a buscar outro tipo de suporte, que pode ser comprado.

Sendo assim, acreditamos que por se tratar de uma temática historicamente recente, ainda não podemos avaliar as consequências de tal atitude. Porém acreditamos ser de suma importância uma relação genuína, baseada no afeto, onde a mãe está em sintonia com o seu bebê para que o mesmo possa tornar-se sujeito.

\section{Referências}

ALMEIDA, S; JABLONSKI, B. O novo (velho) homem: o masculino nos livros de autoajuda. Arq. bras. psicol., Rio de Janeiro, v. 63, n. 2, 2011.

ARIÈS, P. História social da Criança e da Família. Rio de Janeiro: Zahar Editores, 1978.

AULAGNIER, P. O aprendiz de historiador e o mestre-feiticeiro - do discurso identificante ao discurso delirante. São Paulo: Escuta, 1989.

Um intérprete em busca de sentido. São Paulo: Escuta, 1990.

\section{POLÊM!CA | Revista Eletronica da Uej}


BADINTER, E. Um amor conquistado: o mito do amor materno. Rio de Janeiro, Nova Fronteira, 1985.

BARBOSA, P. Z. \& ROCHA-COUTINHO, M. L. (2007). Maternidade: novas possibilidades, antigas visões. Psicologia Clínica, 19(1), 163-185.

BARDIN, L. Análise de conteúdo. São Paulo: Edições 70, 2011.

BAUMAN, Z. O mal-estar da pós-modernidade. Rio de Janeiro: Zahar, 1998.

BRASILEIRO, R.F; JABLONSKI, B. \& FÉRES-CARNEIRO, T. Papéis de gênero e a transição para a parentalidade. Revista PSICO, 33, 2, jul/dez, 289-310. 2002.

DIAS, E. O. A Teoria do Amadurecimento de D. W. Winnicott. São Paulo: DWW Editorial, 2014.

DOLTO, F. Seminario de psicoanálisis con niños. México: Siglo XXI, 1984.

GIDDENS, A. As consequências da modernidade. São Paulo: Unesp, 1991.

JABLONSKI, B. A aferição de atitudes de jovens solteiros(as) frente à crise do casamento: uma réplica. Cadernos de Psicologia, Série Social e Institucional, 5, 5-21, 1996.

JABLONSKI, B. Até que a vida nos separe: a crise do casamento contemporâneo. $2^{\mathrm{a}}$ ed. Rio de Janeiro: Agir, 1998.

Atitudes frente à crise do casamento. In: FÉRES-CARNEIRO, T. (Ed.). Casamento e família: do social à clínica (pp. 81-95). Rio de Janeiro: NAU, 2001.

Afinal, o que quer um casal? Algumas considerações sobre o casamento e a separação na classe média carioca. In: FÉRES-CARNEIRO, T. (Ed.). Família e casal: arranjos e demandas contemporâneas (pp. 141-168). Rio de Janeiro: Loyolla, 2003.

A divisão de tarefas domésticas entre homens e mulheres no cotidiano do casamento. Rev. Psicologia: Ciência e Profissão, 30, 262-275, 2010.

LAPLANCHE, J.; PONTALIS, J.B. (1982). Vocabulário da psicanálise. 4a ed. São Paulo: Martins Fontes, 2001.

LIPOVETSKY, G. A Era do Vazio. Barueri, SP: Manole, 2005.

MIZRAHI, B.G. A Relação Pais e Filhos Hoje: A Parentalidade e as Transformações no Mundo do Trabalho. Rio de Janeiro: Editora PUC-Rio, 2004.

MOURA, S. M. S. R., ARAÚJO, M. F. (2004). A maternidade na história e a história dos cuidados maternos.

Rev. Psicologia: Ciência e Profissão. 24(1), 44 - 55.

ROCHA-COUTINHO, M. L. (2003). Quando o executivo é uma dama: a mulher, a carreira e as relações familiares. In T. Féres-Carneiro (Ed.), Família e casal: arranjos e demandas contemporâneas. Rio de Janeiro: Ed. da PUC-Rio.

. Novas opções, antigos dilemas: mulher, família, carreira e relacionamento no Brasil. Temas em Psicologia da SBP, 12(1), 2-17, 2004.

ROUDINESCO, E. A família em desordem. Rio de Janeiro: Jorge Zahar, 2003. 
WINNICOTT, D. W. A preocupação materna primária. In: . Da pediatria à psicanálise: obras escolhidas (pp. 399-405). Rio de Janeiro: Imago, 1956/2000.

[1945] Desenvolvimento emocional primitivo. In: Textos selecionados: da Pediatria à Psicanálise. Rio de Janeiro: Francisco Alves, p. 269-285, 1978.

[1962] Provisão para a criança na saúde e na crise. In: .O ambiente e os processos de maturação. Porto Alegre: Artes Médicas, p. 62-69. 1990.

O ambiente e os processos de maturação: estudos sobre a teoria do desenvolvimento emocional. Porto Alegre: Artmed, 1983.

Os bebês e suas mães. São Paulo: Martins Fontes, 1998.

A família e o desenvolvimento individual. $2^{\circ}$ ed. São Paulo: Martins Fontes, 2001.

Recebido em: 05/10/2015.

Aceito em: 13/11/2015. 